\section{Voices from a wilderness}

SIR - We appeal for help to the editorial staff of Nature, to our colleague scientists and to the World Federation of Scientific Workers.

We are research workers of Jewish origin. More than two years ago, we came to the decision to leave the Soviet Union and accordingly applied for permission for our families to leave the country for Israel. Soviet law and present practices gave us reason to hope for a quick departure from the country since none of us has ever dealt with state or connected with the security of the Soviet Union. Yet for more than two years we have been denied permission to leave, without reference to the Soviet legal code and without legal or lawful justification.

It seems that considerations in big politics do not take human lives into account.

We doubt whether our colleagues in the West realize what happens if a scientist in the Soviet Union declares his decision to leave the and we are deprived of any possibility of continuing with our scientific research. The doors of scientific institutions, laboratories, seminars, conferences and symposia, editorial offices and publishing houses are shut in our faces. We are being deprived of our scientific degrees.

We feel that the danger of our creative death is becoming more and more real. Any scientist will understand what a two or three year break in scientific work means; and nobody can tell us how long our deprivation will last. Nobody is interested in our qualifications; nobody needs our work here.

Having lost our jobs, we find ourselves in a hard and humiliating financial position. We are anxious about the fate of our families; many of us have small children. We have in fact been thrown out of society, but at the same time we are not allowed to leave the Soviet Union.

All this has naturally had a harmful effect on our health - nervous depressions, hypertonic crises and other diseases have become our permanent companions. Our children are also affected.

We are in a situation where we can count only on the support and solidarity of our colleagues abroad, on their help and sympathy. Our voice in the Soviet Union is really a voice in the wilderness, our fate is of no interest to anybody and nobody answers 316 military secrets or with any questions country. Almost all of us have lost our jobs

our complaints or petitions.

We understand that you all face important problems of your own, but hope that the fate of individual scientists - your colleagues - is also important and not a matter of indifference to you. For the world of science is common for everyone; it has common ethics and morals.

Indeed, our fate is closely connected with the attainment of lawfulness, the observance of the norms and rules of international pacts and human rights declarations, with the fulfilment of the Helsinki agreements and with adherence to humanitarian principles - with everything that makes possible mutual trust and mutual understanding between nations.

We are sure that struggle for the attainment of these principles is part and parcel of the struggle for peace and detente.

Doctor of Science, Mathematics and L.A. DIKII Atmospheric Research, Moscow 125040, Leningradski Av. 28, Apt. 59

G.A. FreimaN

Professor of Mathematics, Moscow 117526, Vernadskogoaw., 91-1-119

M.I. FreidLiN

Doctor of Mathematics, Moscow 117526, ul. 26 Bakinskih komissargo 12-3-179

I.S. IRLIN

MD, Doctor of Science, 129626, Moscow, Novoalekseevskaya str. 13, Build. 1, Apt 54 A.L. VASILEVSKY

Candidate of Science, Docent, Senior Scientific Fellow in Applied Linguistics, Moscow 111401, 3 Vladimirskaya Street 26, Build. 1, Apt 6

M.I. REITMAN

Candidate of Science, Docent, Senior Scientific Fellow in Applied Mathematics, Moscow 121562, Davydkovskaya 38, Apt 176

S.A. KATZ

Doctor of Physics and Mathematical Science, Moscow, Vedenskago Street, 13, Build. 1, Apt

Ya. V. MedvedKov

Doctor of Science (Geogz) Moscow, Leninski Prosp., 123, Kor. 1, Apt 318

V.A. GODYAK

(Plasma Physics) Candidate of Science, Senior Research Fellow, Michwinsky Prosp. 51, Cerp. 3, Apt 156, Moscow 117192

V.N. SOYFER

Doctor of Biology, Moscow, Chertandskaya ul. 35, Build. 2, Fl.131

\section{An acid test}

\section{SERC's plans}

SIR - In your excellent leading article of 26 November (p.295) you state that the Science and Engineering Research Council "has just put off a plan to break new ground in the fashionable field of molecular electronics". It is certainly true that we are unable to fund in an adequate fashion programmes that certainly deserve support, but in the particular case of molecular electronics we are currently planning to increase our support of research in this potentially exciting area. Inevitably this means we have to cut back on other deserving areas.

$$
\text { B.W. OAKLEY }
$$

Science and Engineering Research Council, Swindon, UK

SiR - The objection of Darnbrough et al. (Nature 26 November, p.294) to data in our BioSystems paper on the origin of life is based, according to correspondence, on experiments with ATP at $p \mathrm{H} 11$, where ATP is unstable. On page 162 of the article, which they cite inaccurately, experiments at $p \mathrm{H} \mathrm{7.2}$ are described. This technical detail (that is, experiments at $p \mathrm{H} 7.2$ ) is critical in judging their statements about plausibility. For readers interested in confirming this, the correct reference is Fox and Nakashima, BioSystems 12, 155-166; 1980.

SidNEY W. FoX

University of Miami,

Florida, USA

\section{Literary anarchy}

SIR - The problems raised in recent letters (7 May, p.7, 28 May, p.278) about literature search and by Dana L. Roth (8 October, p.422) about recruiting librarians with subject expertise may be solved if and when today's librarians turn towards Anarchism as in the following: "How to be an Anarchistic but Indispensable Librarian" -

(1) Make your own rules so that you can change and interpret them according to circumstances.

(2) Always act contrary to the rules

(3) Use flexible opening hours; go out as often as possible so that your readers are happy if and when they see you.

(4) Differentiate your catalogue cards.

(5) $a$. Articles in authors' names may or may not be written after the names; sometimes split names are typed as whole ones.

$b$. Use alternatingly full and abbreviated journal titles; use different abbreviations for the same title. $c$. Keywords are typed above the author's name or underlined; singular, plural, adjective and complex word forms are to be used.

$d$. Never use see- or see also-references. $e$. Never correct errors.

(6) Foreign characters are alternatingly transliterated or not.

(6) 1. Greek alphabet: transliterate or write in full ( $\gamma=\mathrm{g}$ or gamma).

(6) 2. Figures are alphabeticized before or after plain characters but they may also be written in full in different languages.

(6) III. Chemical substances will be found alternatingly under the common name, the scientific name, the product formula or the gross formula.

(7) Print a catalogue of current journal titles but do not include the years or volume numbers your collections start with.

(9) Move your books and journals regularly.

(X) Take holidays without warning anybody; never tell the date of your return.

(11) Never compose statistics with exact numbers but make rough estimates.

(12) Avoid management techniques (whatever they may be).

(13) Help your readers as well as possible; talk at least half an hour with every new customer and at least one hour a week with regular visitors.

(14) Be fraternal: send now and then somebody on to other libraries

(eight) Never write anything down but don't try to remember everything either.
(Four) Make sufficient catalogues: monographs and reprints each have separated authors, journals and serials, systematic, and keywords catalogues; put all these catalogues in one piece of furniture.

If you do this and a lot of other things, you deserve the title "Anarchistic Librarian"; but: your customers will be satisfied and you have made yourself indispensable.

G. MERTENS

Katholieke Universiteit,

(Anarchist) Librarian

Leuven, Belgium 